\title{
Bioprosthetics and repair of complex aerodigestive defects
}

\author{
Brooks Udelsman ${ }^{1}$, Douglas J. Mathisen ${ }^{2}$, Harald C. Ott ${ }^{2}$ \\ ${ }^{1}$ Division of General Surgery, ${ }^{2}$ Division of Thoracic Surgery, Massachusetts General Hospital, Boston, MA, USA \\ Correspondence to: Harald C. Ott, MD. Division of Thoracic Surgery, Massachusetts General Hospital, 55 Fruit Street, Boston, MA, USA. \\ Email: hott@mgh.harvard.edu.
}

\begin{abstract}
Aerodigestive defects involving the trachea, bronchi and esophagus are a result of prolonged intubation, operative complications, congenital defects, trauma, radiation and neoplastic disease. The vast majority of these defects may be repaired primarily. Rarely, due the size of the defect, underlying complexity, or unfavorable patient characteristics, primary repair is not possible. One alternative to primary repair is bioprosthetic repair. Materials such as acellular dermal matrix and aortic homograft have been used in a variety of applications, including closure of tracheal, bronchial and esophageal defects. Herein, we review the use of bioprosthetics in the repair of aerodigestive defects, along with the unique advantages and disadvantages of these repairs.
\end{abstract}

Keywords: Bioprosthetic; trachea; aortic homograft; acellular dermal matrix; regenerative medicine

Submitted Dec 15, 2017. Accepted for publication Dec 21, 2017.

doi: 10.21037/acs.2018.01.13

View this article at: http://dx.doi.org/10.21037/acs.2018.01.13

\section{Introduction}

The airway serves as a passive conduit for the passage of air during respiration and a facilitator for clearance of secretions. The esophagus, on the other hand, is an active conduit for oropharyngeal sections and food particulate. Both of these hollow organs travel in close anatomic proximity throughout the chest and are separated only by a thin layer of connective tissue. Any injury or disease affecting one or both can lead to a loss of domain and result in connection of the two lumens. Such a fistulous connection inevitably leads to airway contamination with secretions, food and possibly gastric secretions, in the setting of gastroesophageal reflux. Ideally, repair of either organ restores their integrity and their basic functions. Primary repair is the preferred method for correction of defects to the aerodigestive track. In cases of substantial tissue loss or stenosis, circumferential resection and subsequent reconstruction may be necessary. Through a variety of techniques, including neck flexion, laryngeal release, airway mobilization and hilar release, tracheal defects of up to $5 \mathrm{~cm}$ may be closed primarily in the ideal patient (1). Similarly, large esophageal defects may be repaired through resection and repair either with or without gastric or colonic conduits. A key element of the successful repair of aerodigestive fistula is the interposition of robust vascularized tissue (2). It has become an exceptionally rare circumstance in which primary repair of a tracheal defect is not possible and is generally associated with rare neoplastic diseases such as adenoid cystic carcinoma $(3,4)$. After reviewing our institution's experience over an 8 -year period, we found only 8 instances out of 342 airway procedures in which an alternative to primary repair or permanent tracheostomy was required (5).

In scenarios in which primary repair is not an option, one alternative is the use of bioprosthetic material. These materials are derived from cadavers and treated chemically and physically to remove cells and other immunologically reactive tissue. Compared to traditional synthetic prosthesis, bioprosthesis have several advantages, including improved handling, minimal immunogenic response and potentially decreased risk of bacterial seeding and infection due to a high degree of biocompatibility, especially in the absence of crosslinking. Herein, we will focus on the current state of bioprosthetic repair of tracheal, bronchial and esophageal defects. We will include bioprosthetic repairs in which the defect was limited to either the airway or the esophagus, as well as repairs involving aerodigestive 
fistulas. Other methods of repair, such as tracheal transplantation, autologous reconstruction and tissue engineering approaches represent potential alternatives $(6,7)$, but are beyond the scope of this scope of this current review.

\section{Bioprosthetic materials}

Bioprosthetic materials are derived from cadaveric tissue through chemical treatment, freezing, or lyophilization to remove or denature immunologically reactive cellular components and to eliminate any possible pathogens. The remaining extra-cellular matrix can then serve as a scaffold for tissue ingrowth while functioning as an airtight seal for the repaired defect. While there is evidence that some bioprosthetics may retain active chemoattractants, binding sites and growth factors within the preserved extra-cellular matrix, these factors do not elicit acute rejection of the graft and do not necessitate immunosuppressive treatments (8). Additionally, bioprosthetics have a potential advantage compared to traditional prosthetic materials through theoretic resistance to bacterial and fungal colonization, which can doom any repair. Given the constant exposure of the airway and esophagus to oral flora and the atmosphere with its associated pathogens, resistance to infection is a unique requirement to aerodigestive repair. To date, the most common materials used in the bioprosthetic repair of aerodigestive defects are aortic homograft and acellular dermal matrix.

\section{Acellular dermal matrix}

Acellular dermal matrix came into use in the 1990s and was first used for treatment and temporary coverage of full thickness burns $(9,10)$. Over the past two decades it has been adopted with varying success in a variety of applications including abdominal wall reconstruction, breast reconstruction and repair of pharyngeal defects $(8,11)$. In 2006, Bozuk et al. reported the repair of an esophageal defect with acellular dermal matrix (12) and in $2008 \mathrm{Su}$ et al. reported the use of acellular dermal matrix in the repair of the trachea in a patient who presented with a large tracheoesophageal fistula (13). Acellular dermal matrix is commercially available from human and animal sources in various sizes and thicknesses. It is harvested from cadavers and undergoes processing that removes donor cells, but leaves the extracellular matrix intact. This processing eliminates the need for post-implantation immunosuppression. Depending on packaging, it may require rinsing and/or rehydration in saline at time of implantation.

\section{Aortic homograft}

Aortic homografts, also sometimes referred to as allografts, have been used clinically in aortic valve replacement and in arch repair since the 1960s (14,15). Experimentally, aortic homografts were first used in tracheal repair in a canine model by Pressman and Simon in 1959 (16). During that same time period, two case reports emerged regarding the use of aortic homograft as a circumferential conduit in esophageal repair. However, information regarding these repairs is scarce and will not be further explored in this review (17). The first report of clinical use in airway repair was in 1999 by Chahine et al. and is discussed in the following section (18). Grafts are harvested from cadaveric donors, disinfected and packaged in a cryopreservation solution in which they can be stored for 10 years. They are commercially available and can be used off the shelf within 30 minutes of opening. The graft is thawed and rinsed prior to implantation. The graft may be perforated with a 16-gauge needle prior to implantation to encourage tissue ingrowth without compromise to the airtight competency of the repair. Given the method of disinfection and cryopreservation, most of the immunoreactive components of the donor are removed and there is no reported risk of rejection or need for post-operative immunosuppression.

\section{Other bioprosthetics}

Aortic homograft and acellular dermal matrix are the only bioprosthetics currently used in clinical practice in the repair of large airway defects. Experimental work using canine models and freeze-dried tracheal homografts was performed by several investigators in the 1950s and 1960s, but abandoned due to development of stenosis and necrosis of the graft $(19,20)$. In the 1990s, clinical attempts were made using tracheal homografts in a pediatric population to treat long segment tracheal stenosis; however, frequent use of stents was required and many patients required serial bronchoscopy and debridement due to development of excessive granulation tissue $(21,22)$. Due to these difficulties and a lack of commercial availability, tracheal homografts have largely been abandoned, with an exception reserved for tissue engineering approaches which are beyond the scope of this review. 


\section{Pre-operative concerns}

In the unique event that a patient cannot tolerate a primary repair and bioprosthetic repair is being considered, optimization prior to any intervention is critical. Patients should be referred to a high-volume center for evaluation by a surgical team experienced in complex airway repair. Functional status should be carefully assessed to determine likelihood of complications and post-operative recovery. Prognosis should be addressed and overall goals of the procedure established, especially in patients suffering from neoplastic disease. Principles of aerodigestive fistula repair such as interposition of viable tissue, preoperative clearance of pulmonary infections and postoperative extubation apply. While bioprosthetics are theoretically resistant to bacterial seeding, they represent a non-vascularized foreign body until fully incorporated and are thus at risk for colonization. Temporization with tracheostomy, stenting, or $\mathrm{T}$ tube to allow for treatment of underlying infection is preferable over placement of a bioprosthetic into a contaminated field.

\section{Clinical use}

Over the past 20 years, 29 patients have undergone bioprosthetic repair for complex tracheal, bronchial, or esophageal defects, including 9 with aerodigestive fistulas. Of those 29 patients, 10 underwent repair with acellular dermal matrix (Table 1), while the remaining 19 underwent repair with aortic homograft (Table 2). In those repaired with acellular dermal matrix, the underlying pathology included leaks after esophagectomy, primary malignancy, post-intubation injury and AIDS associated esophagitis (5,12,13,23-26). Acellular dermal matrix was used in the repair of the airway in six cases and repair of the esophagus in four cases. In patch repair of the airway and the esophagus, acellular dermal matrix proved reliable with relatively minimal post-operative complications. These were generally limited to benign stricture or excessive granulation tissue development, which was managed nonoperatively with serial dilation or debridement respectively. In the single patient with a circumferential repair, significant complications were encountered, including graft slippage requiring reoperation and prolonged tracheostomy (26).

In patients who underwent treatment with aortic homograft, bioprosthetic repair was limited to the trachea and bronchus (5,18,27-31). The underlying pathology within this group was more heterogeneous than that of patients repaired with acellular dermal matrix and included a substantial percent with tracheal neoplastic disease $(42 \%)$. As in those patients treated with acellular dermal matrix, aortic homograft patch repair was successful with complications limited primarily to excessive formation of granulation tissue and stenoses that could be treated bronchoscopically. In contrast to patients treated with acellular dermal matrix, 11 patients underwent a circumferential or near circumferential repair with a tubularized graft composed of aortic homograft. In the majority of these cases, prolonged stenting of several months to years was required. In addition, more frequent and severe complications were encountered, including graft migration, anastomotic dehiscence and sternal dehiscence, all of which required reoperation. The use of an interpositional graft composed of aortic homograft was used only for temporization in one patient until redo lung transplantation could be performed three days later (27). As a result, there are only 10 patients who underwent interpositional bioprosthetic repair with post-operative follow-up beyond a few days.

With regards to use as a patch, both bioprosthetics provide an airtight closure with minimal significant complications. In this function, acellular dermal matrix and aortic homograft represent a viable option for the management of aerodigestive defects that, either due to size or complexity, exceed the limits of a standard primary repair. Given the complexity of these procedures, it is prudent to buttress any repair with healthy vascularized tissue. While select cases may exist in which buttressing can be omitted in simple primary repair (32), in the complicated cases described above it is preferable to use healthy, vascularized tissue to support the bioprosthesis, prevent malacia and provide protection in case of a leak. Indeed, in only four instances has an attempt at repairing the airway without an accompanying buttress been reported. In these four patients, two died within 1 month and a third underwent excision of the graft and repeat lung transplantation after only three days $(5,18,27,28)$.

Circumferential or near circumferential repair with a tubular interpositional graft is a major challenge in surgery of the airway. Attempts at repair with acellular dermal matrix and early attempts with aortic homograft failed secondary to graft migration and dehiscence $(26,28)$. Later circumferential repairs with aortic homograft or fresh allograft have been more successful and benefited from the use of long-term stenting $(29,31)$. The most recent work reported by Martinod et al. is promising, with longterm follow-up demonstrating a stable repair even after 


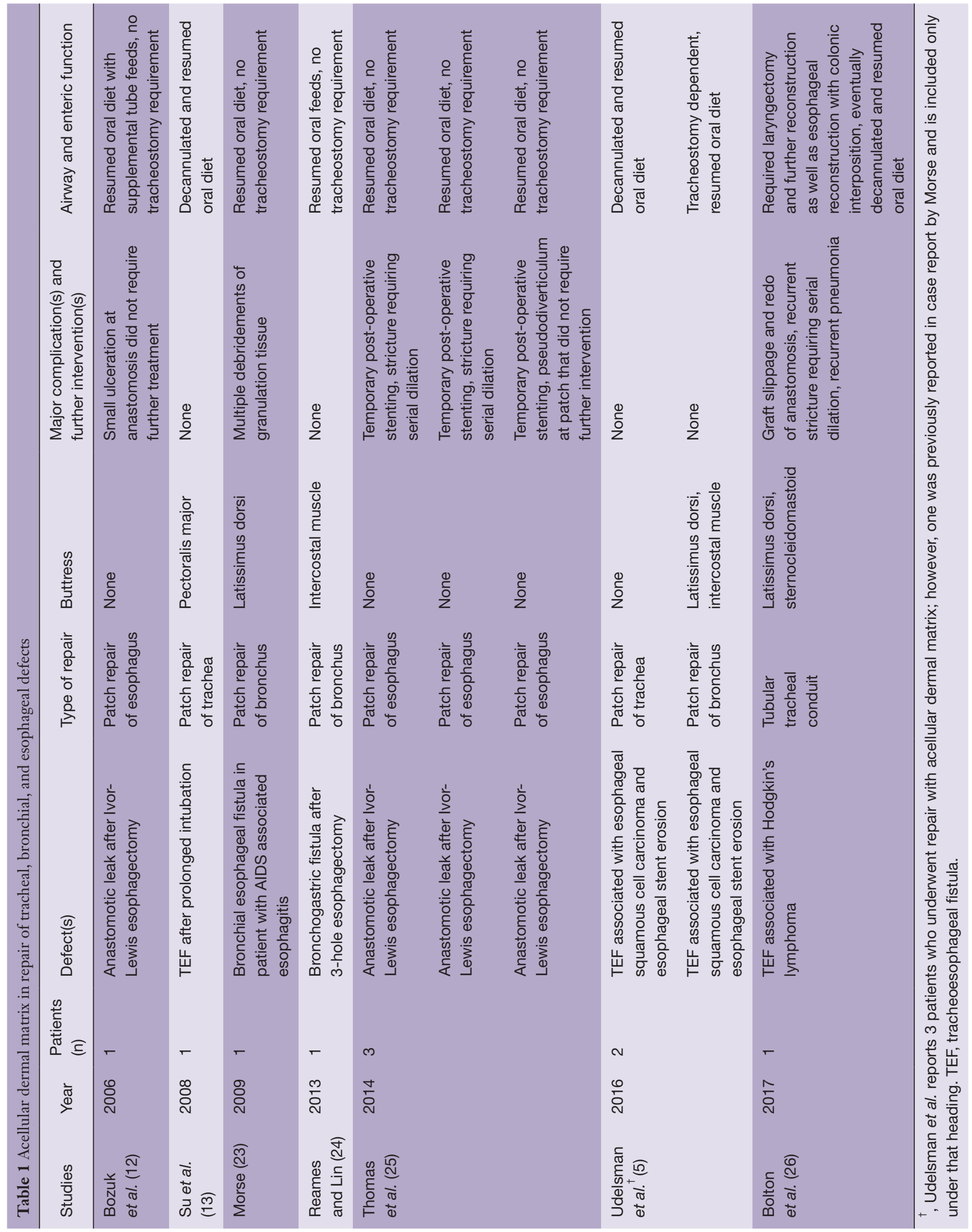




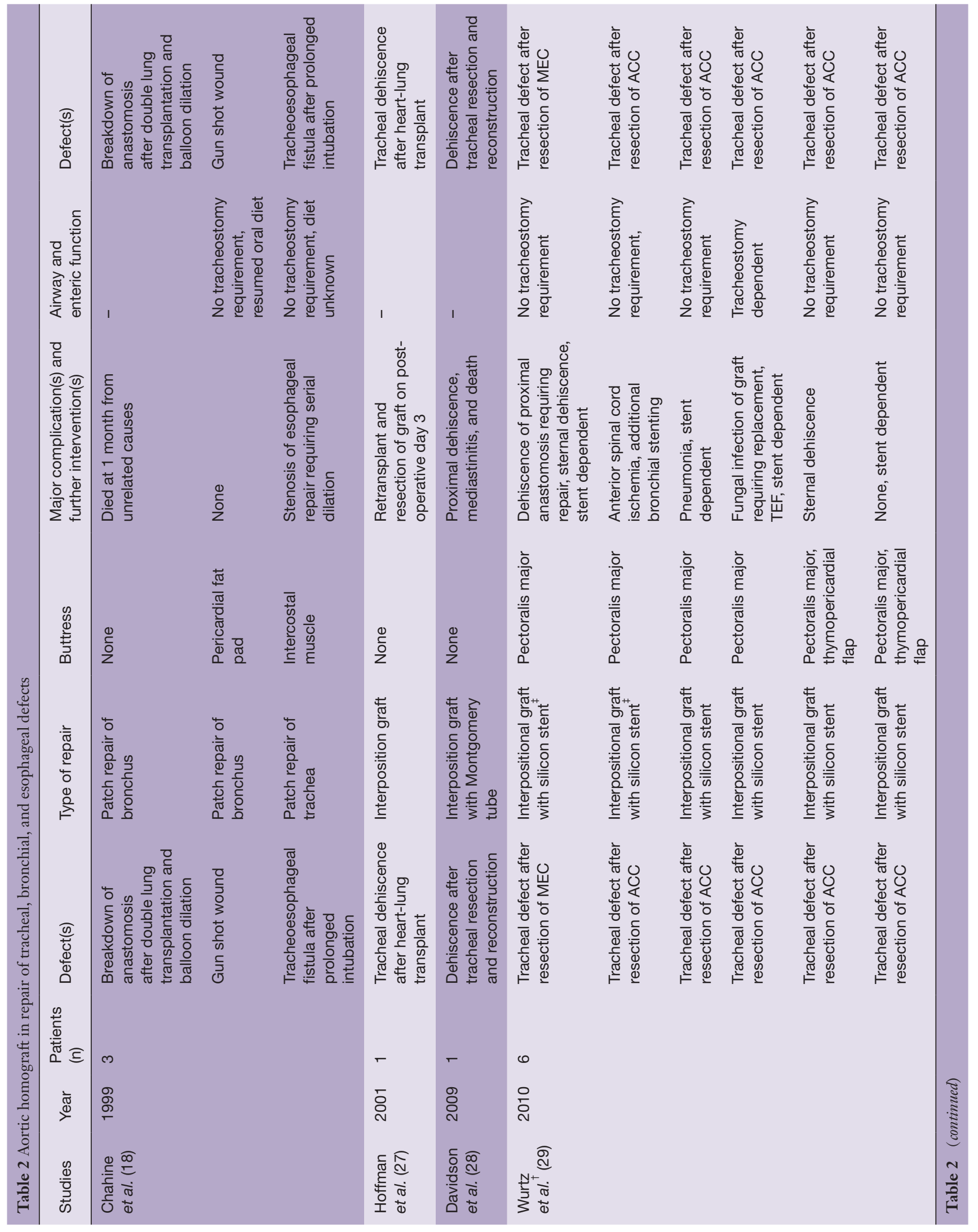




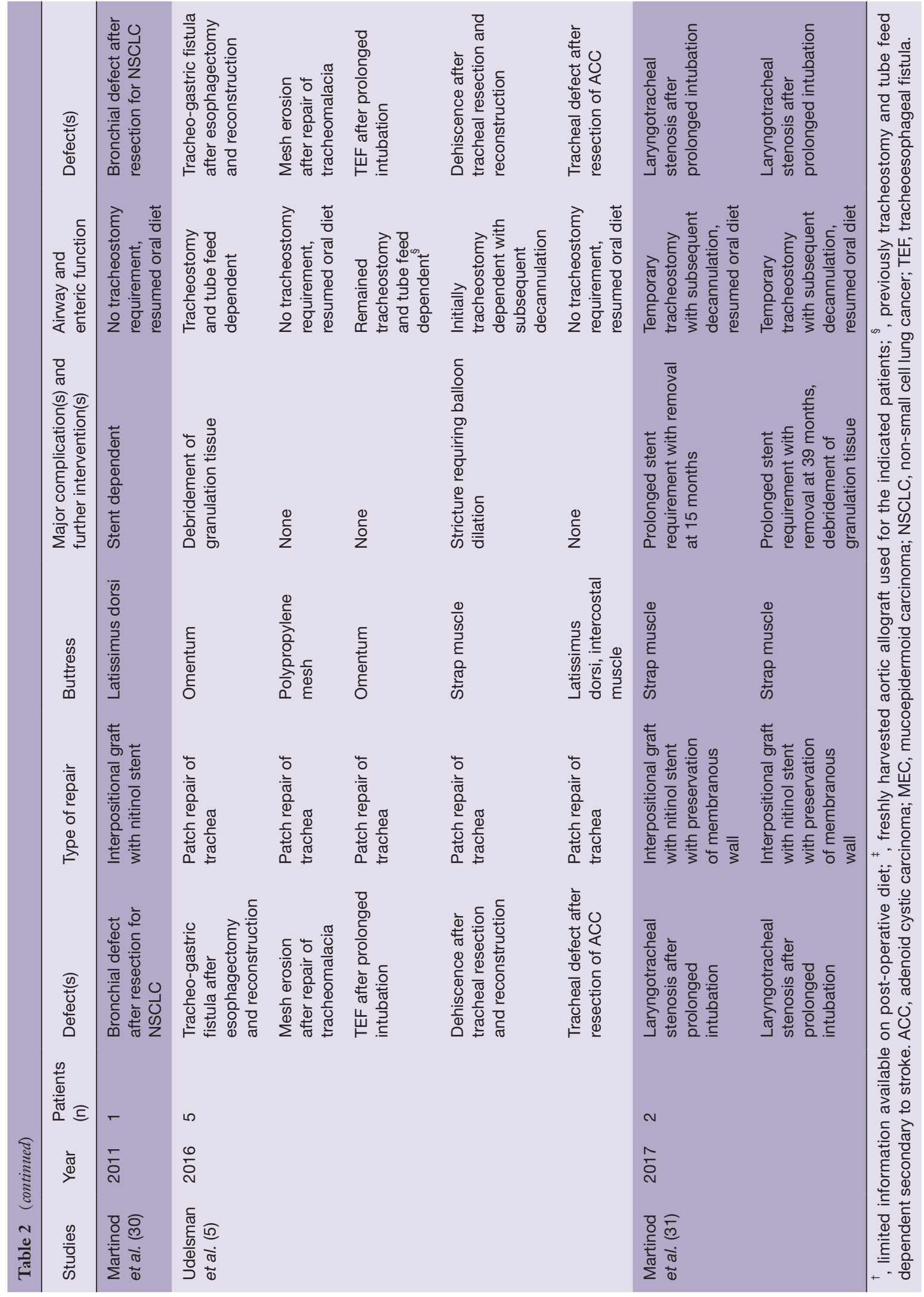


stent removal in patients undergoing reconstruction for benign laryngotracheal stenosis. It remains to be seen if the robustness of the repair is maintained in the challenging situation of underlying malignancy or concomitant enteric fistula.

Finally, the exact mechanisms through which bioprosthetics aid in the repair of aerodigestive defects requires further investigation. In the majority of studies in which the bioprosthetic repair has been tracked through long-term follow up, "healing" occurs with deposition of granulation tissue, contraction and scaring $(5,29)$. This process highlights the need for frequent bronchoscopic surveillance with debridement and balloon dilation if needed. At no point in previous reports has there been substantive evidence of cartilage formation. However in their recent follow up of two patients with near circumferential aortic homograft repair, Martinod et al. report the development of cartilage derived from recipient cell lines. They propose a mechanism of "in vivo tissue engineering", in which remaining donor cells within the extracellular matrix release proangiogenic, chemoattractants and growth factors which stimulate repopulation of the graft with recipient progenitor cells. They attribute the success of their work in part to storage of cryopreserved aortic grafts at $-80^{\circ} \mathrm{C}$ rather than $-150^{\circ} \mathrm{C}$, which they report helps preserve donor growth factors and protected cells within the extracellular matrix (31). However, several questions regarding this repair remain unanswered, including how the graft becomes revascularized and the mechanistic pathway by which growth factors orchestrate the complex migration and differentiation of circulating host cells.

\section{Conclusions}

Major advances in airway surgery during the $20^{\text {th }}$ century have made the vast majority of aerodigestive defects amenable to primary repair. In the last 20 years, bioprosthetic repairs has emerged as an alternative in rare cases in which primary repair is not an option. The decision to forgo primary repair and elect for bioprosthetic repair should only be made after careful review at a center experienced in complex airway surgery.

Both acellular dermal matrix and aortic homograft have been tested in numerous settings as a patch repair. When used in conjunction with a healthy well vascularized buttress, these bioprosthetics provide a durable airtight seal preserving the competency of the airway and allow for a natural healing process to occur. In the case of anastomotic leak involving the esophagus or a gastric conduit, acellular dermal matrix has also provided a competent repair and spared patients further resection and reconstruction. In addition to these successful patch repairs of the trachea, bronchus and esophagus described above, aortic homograft has been used in the reconstruction of the larynx after partial laryngectomy in a series of 15 patients with neoplastic disease reported by Zeitels et al. As in the trachea, these bioprosthetic repairs of the larynx allowed the majority of patients to achieve decannulation, preserve phonation and resume an oral diet (33). While the focus of this review is on the repair of defects involving the trachea, bronchus and esophagus, the laryngeal repairs reported by Zeitels et al., along with the work by Sinha et al. describing aortic homograft reconstruction of the pharynx, demonstrate both the versatility and robustness of bioprosthetics when used in patch repair and with a tissue buttress (11).

The more difficult situation of circumferential airway repair is under continuous investigation. Multiple proposed repair modalities have been explored, including transplantation, tissue engineering and as discussed above, bioprosthetic repair. However, the results of aortic homograft repair with longstanding airway stenting by Martinod et al. are encouraging (31).

In regards to future use of bioprosthetics, both as patches and circumferential interpositional conduits, several questions persist. First, it remains to be seen whether a bioprosthetic repair can withstand the additional burden of adjuvant chemotherapy and radiotherapy in patients with malignant neoplastic disease. Furthermore, when a patch repair is planned in a patient with neoplastic disease, diligence must be taken to ensure adequate resection and negative margins. It may be a challenge to balance adequate oncologic resection while leaving enough native tissue to facilitate bioprosthetic repair. Moreover, the role of bioprosthetic repair in a palliative setting when complete resection is not possible remains undetermined. Lastly, the role for bioprosthetics in a still growing pediatric population is unclear. Chahine et al. have reported successful patch repair using aortic homograft in two pediatric patients with minimal morbidity at 2-year follow up (18); however, the growth potential of a repair with these materials remains to be examined, especially if used as a tubular interpositional graft is uncertain. These questions will quickly develop clinical relevancy as bioprosthetics become a more accepted treatment option for complex patients with defects unsuitable for primary repair. 


\section{Acknowledgements}

None.

\section{Footnote}

Conflicts of Interest: The authors have no conflicts of interest to declare.

\section{References}

1. Grillo HC. Tracheal replacement: a critical review. Ann Thorac Surg 2002;73:1995-2004.

2. Muniappan A, Wain JC, Wright CD, et al. Surgical treatment of nonmalignant tracheoesophageal fistula: a thirty-five year experience. Ann Thorac Surg 2013;95:1141-6.

3. Pearson FG, Thompson DW, Weissberg D, et al. Adenoid cystic carcinoma of the trachea. Experience with 16 patients managed by tracheal resection. Ann Thorac Surg 1974;18:16-29.

4. Fabre D, Kolb F, Fadel E, et al. Successful tracheal replacement in humans using autologous tissues: an 8-year experience. Ann Thorac Surg 2013;96:1146-55.

5. Udelsman BV, Eaton J, Muniappan A, et al. Repair of large airway defects with bioprosthetic materials. J Thorac Cardiovasc Surg 2016;152:1388-97.

6. Law JX, Liau LL, Aminuddin BS, et al. Tissue-engineered trachea: A review. Int J Pediatr Otorhinolaryngol 2016;91:55-63.

7. Abouarab AA, Elsayed HH, Elkhayat H, et al. Current Solutions for Long-Segment Tracheal Reconstruction. Ann Thorac Cardiovasc Surg 2017;23:66-75.

8. Jansen LA, De Caigny P, Guay NA, et al. The evidence base for the acellular dermal matrix AlloDerm: a systematic review. Ann Plast Surg 2013;70:587-94.

9. Livesey SA, Herndon DN, Hollyoak MA, et al. Transplanted acellular allograft dermal matrix. Potential as a template for the reconstruction of viable dermis. Transplantation 1995;60:1-9.

10. Wainwright D, Madden M, Luterman A, et al. Clinical evaluation of an acellular allograft dermal matrix in fullthickness burns. J Burn Care Rehabil 1996;17:124-36.

11. Sinha UK, Chang KE, Shih CW. Reconstruction of pharyngeal defects using AlloDerm and sternocleidomastoid muscle flap. Laryngoscope 2001;111:1910-6.

12. Bozuk MI, Fearing NM, Leggett PL. Use of decellularized human skin to repair esophageal anastomotic leak in humans. JSLS 2006;10:83-5.

13. Su JW, Mason DP, Murthy SC, et al. Closure of a large tracheoesophageal fistula using AlloDerm. J Thorac Cardiovasc Surg 2008;135:706-7.

14. Stelzer P, Elkins RC. Homograft valves and conduits: applications in cardiac surgery. Curr Probl Surg 1989;26:381-452.

15. Ross DN. Homograft replacement of the aortic valve. J Cardiovasc Surg (Torino) 1965;5:Suppl:89-94.

16. Pressman JJ, Simon MB. Tracheal stretching and metaplasia of the tracheal rings from cartilage to bone following the use of aortic homografts. Am Surg 1959;25:850-6.

17. Rogers FA. Restoration of the thoracic esophagus with aortic homograft following palliative subtotal esophagectomy. Am J Surg 1958;96:38-42.

18. Chahine AA, Tam V, Ricketts RR. Use of the aortic homograft in the reconstruction of complex tracheobronchial tree injuries. J Pediatr Surg 1999;34:891-4.

19. Marrangoni AG. Homotransplantation of tracheal segments preserved by lyophilization; an experimental study. J Thorac Surg 1951;21:398-401.

20. Greenberg SD. Tracheal reconstruction: an experimental study. Arch Otolaryngol 1960;72:565-74.

21. Jacobs JP, Elliott MJ, Haw MP, et al. Pediatric tracheal homograft reconstruction: a novel approach to complex tracheal stenoses in children. J Thorac Cardiovasc Surg 1996;112:1549-58; discussion 1559-60.

22. Elliott MJ, Haw MP, Jacobs JP, et al. Tracheal reconstruction in children using cadaveric homograft trachea. Eur J Cardiothorac Surg 1996;10:707-12.

23. Morse CR. Repair of bronchial esophageal fistula using Alloderm. Ann Thorac Surg 2009;88:1018-9.

24. Reames BN, Lin J. Repair of a complex bronchogastric fistula after esophagectomy with biologic mesh. Ann Thorac Surg 2013;95:1096-7.

25. Thomas M, Allen MS, Shen KR, et al. A novel use of human acellular dermis for conduit salvage after esophagectomy. Ann Thorac Surg 2014;97:1459-63.

26. Bolton WD, Ben-Or S, Hale AL, et al. Reconstruction of a Long-Segment Tracheal Defect Using an AlloDerm Conduit. Innovations (Phila) 2017;12:137-9.

27. Hoffman TM, Gaynor JW, Bridges ND, et al. Aortic homograft interposition for management of complete tracheal anastomotic disruption after heart-lung transplantation. J Thorac Cardiovasc Surg 2001;121:587-8. 
28. Davidson MB, Mustafa K, Girdwood RW. Tracheal replacement with an aortic homograft. Ann Thorac Surg 2009;88:1006-8.

29. Wurtz A, Porte H, Conti M, et al. Surgical technique and results of tracheal and carinal replacement with aortic allografts for salivary gland-type carcinoma. J Thorac Cardiovasc Surg 2010;140:387-93.e2.

30. Martinod E, Radu DM, Chouahnia K, et al. Human transplantation of a biologic airway substitute in conservative lung cancer surgery. Ann Thorac Surg 2011;91:837-42.

Cite this article as: Udelsman B, Mathisen DJ, Ott HC. Bioprosthetics and repair of complex aerodigestive defects. Ann Cardiothorac Surg 2018;7(2):284-292. doi: 10.21037/ acs.2018.01.13
31. Martinod E, Paquet J, Dutau H, et al. In Vivo Tissue Engineering of Human Airways. Ann Thorac Surg 2017;103:1631-40.

32. Camargo JJ, Machuca TN, Camargo SM, et al. Surgical treatment of benign tracheo-oesophageal fistulas with tracheal resection and oesophageal primary closure: is the muscle flap really necessary? Eur J Cardiothorac Surg 2010;37:576-80.

33. Zeitels SM, Wain JC, Barbu AM, et al. Aortic homograft reconstruction of partial laryngectomy defects: a new technique. Ann Otol Rhinol Laryngol 2012;121:301-6. 